\title{
Re-entrained road dust PM10 emission from selected streets of Krakow and its impact on air quality
}

\author{
Marek Bogacki ${ }^{1, *}$, Marian Mazur ${ }^{1}$, Robert Oleniacz ${ }^{1}$, Mateusz Rzeszutek $^{1}$, and Adriana \\ Szulecka ${ }^{1}$ \\ ${ }^{1}$ AGH University of Science and Technology, Department of Environmental Management and \\ Protection, A. Mickiewicza 30 Av., 30-059 Krakow, Poland
}

\begin{abstract}
Scientific research studies conducted in various parts of the world confirm that PM10 concentrations in urban air depend to a great extent on the resuspension processes of the dust deposited on the road surface. The paper presents the results of the study related to the determination of the re-entrained PM10 emissions from four selected streets of Krakow (Southern Poland) together with the assessment of its impact on air quality. Examined streets are characterised by different traffic intensity (from 500 to over 20000 vehicles per day) and individual vehicle structure. Dust material sampling and estimation of the PM10 emission were conducted according to the U.S. EPA methodology (AP 42 Fifth Edition). Two variants of sample collection were applied: from the road surface including the area at the curb (4 streets) and from the road surface alone (1 street). The estimates of resuspended road dust emission as well as the reference values derived from the U.S. EPA guidelines were used to assess the impact of this emission on the PM10 levels in the air at the location of one of the analysed streets. This assessment was conducted using the CALINE4 mathematical model. The study showed that the PM10 emissions from the re-entrained road dust can be responsible for up to 25 $\%$ in the winter and $50 \%$ in the summer of the total PM10 concentrations in the air near the roads.
\end{abstract}

\section{Introduction}

The PM10 fine dust concentrations in the air are determined by the spatio-temporal distribution of its emission as well as the atmospheric propagation factors, which depend on, inter alia, the orography and local meteorological conditions. In urban and industrial regions the exceedances of permitted PM10 levels are commonly observed. This situation frequently results from the presence of numerous low emission sources situated in a small area, usually densely built, which impede the dispersion effectiveness of air pollutants. Particularly susceptible to excessive air pollutant concentrations in the air are the areas located within the street canyons [1-4]. This can be explained by the occurrence of specific

\footnotetext{
*Corresponding author: bogacki@agh.edu.pl
} 
air circulation conditions that are not conducive to unhindered dispersion of pollutants emitted from the road transport [5-6].

PM10 dust in the air can be of the anthropogenic origins, but it can also result from physiochemical reactions between different substances present in the air (secondary organic and inorganic aerosols) [7]. Numerous studies on the PM10 chemical composition conducted for the areas within street canyons point out that the particulate matter does not solely originate from fuel combustion in motor vehicles, but constitutes a mixture of dusts of different origins and individual chemical compositions [8]. In addition to the organic and elementary carbon, the silicates, carbonates, metal oxides, phosphates, secondary organic and inorganic aerosols can be found in dust particles. However the chemical composition, particle size and morphology are determined strictly by the source of origin [9]. Literature studies indicate that particles of less than $100 \mathrm{~nm}$ in diameter are mainly emitted from internal combustion engines and are based on the organic and elementary carbon [10]. Particles with a diameter of 2.5-10 $\mu \mathrm{m}$ and more are emitted primarily from the road surfaces, where the dust originating from industry and energy sector is deposited together with the particulate matter resulting from abrasion of the road surface, car tires and brake pads as well as particles caused by the wind erosion processes and dust loading brought from construction sites, unpaved roads, etc. [7, 11-13]. Passing motor vehicles create a vacuum in the space between the road and car chassis, triggering the entrainment of the dust from the road to the air. Those particles are primarily of the organic origins, including soil dust and organic parts, and the products of abrasion of the vehicle consumables [14].

Many studies conducted worldwide indicate that the resuspended dust emission constitutes a significant share in the PM10 concentrations in the air near the transport routes $[6,8,14-20]$. Research carried out in the US city of Tucson (Arizona) in the winter showed that the fraction of particulate matter from the fuel combustion in car engines and the share of re-entrained road dust ranged from $4-40 \%$ and $30-50 \%$ of the total PM10 concentration in the air, respectively [21]. On the other hand, the study conducted in Barcelona (Spain) [7] pointed out that the ratio of PM10 emissions from automotive engines to PM10 resuspended dust emissions from roads is equal to only 1.2. However, the same emission ratio for PM2.5 particulate matter is equal to 4 .

During the evaluation of the PM10 sources contribution in the background levels in the vicinity of roads, it is of significant importance to unambiguously describe the nature of the street. In the paper [6] the results of measurements carried out for two types of roads were showed. The first type was represented by an urban road located in a street canyon (buildings height of 10-20 m), characterized by heavy traffic (about 20000 vehicles $\cdot$ day $^{-1}$ ) and frequent traffic jams (Zürich, Switzerland) and the second type was represented by a motorway with a traffic density of approx. 50000 vehicles $^{-1 a y}{ }^{-1}$ (Reiden, canton of Lucerne, Switzerland). Obtained results indicated that the level of PM10 concentrations in the air within the street canyon is influenced in $41 \%$ by the dust emitted from car engines, in $38 \%$ by the particles re-entrained from the road surface and in $21 \%$ by the particles originating from brake pads wear. In the case of the motorway, however, these shares are 41,56 and $3 \%$, respectively.

Similar studies executed in different countries in the world have shown unequivocally the significant influence of the dust emitted from the road pavements on air quality, especially in urban areas. Assuming that by the year 2020 the PM10 emission from the internal combustion engines will decrease by 30-45\% but the other emission will remain the same, it should be expected that the resuspended dust emissions share will increase to about $80-90 \%$ (with the current number of road vehicles assumed). In the case of an increase in the number of cars, the share of re-entrained road dust emissions will be even higher [22]. Thus, the actions aiming at the reduction of PM10 emissions into the air cannot be limited merely to the establishment of more restrictive PM10 emission standards from 
internal combustion engines, but should also involve decision making that would lead to radical decrease in the re-entrained road dust emissions by introducing more efficient and intensified road-cleaning techniques [23-25]. Only a major reduction in re-entrained road dust emission will allow many urbanized areas to meet the current European Union standards specifying daily and annual permitted levels of PM10 concentrations [26].

Krakow is one of many Polish cities where PM10 concentrations in the air are exceeded on a regular basis, which is observed especially at the traffic air quality monitoring stations [27]. The aim of the research described in the paper was to estimate the level of reentrained road dust emissions from four selected streets of Krakow and its impact on air quality using one of the analysed streets as an example.

\section{Research methodology}

\subsection{Area of research}

Experimental campaign was conducted on 10.10.2015 from 0:00 to 1:00 in the four selected sections of Krakow streets, characterized by different traffic intensity during the day. In the study two one-lane streets were considered: Lea (500-5 000 vehicles $\cdot$ day $\left.^{-1}\right)$ and Reymonta (5 000-10 000 vehicles.day $\left.{ }^{-1}\right)$ as well as two two-lane streets: Armii Krajowej (10 00020000 ) and Krasinskiego (over 20000 vehicles.day ${ }^{-1}$ ). All of the analysed streets are located in the centre of Krakow. Two of them (i.e. Lea St. and Krasinskiego Av.) are situated within the street canyons.

\subsection{Dust sampling methodology}

Samples of dust material from selected road sections were collected according to the American Environmental Protection Agency (EPA) guidelines [28, 29]. Two variants of sampling were considered: (1) from the road surface and the area at the curb (all streets), and (2) only from the road surface (Reymont St.). Three samples of dust material were collected from each street. Total weight of samples collected from every street exceeded 0.5 $\mathrm{kg}$. The sampling areas, perpendicular to the axis of the road, were strip-shaped with a width of $100 \mathrm{~cm}$. Samples were collected with a brush and a dustpan. Dust sampling was carried out 15 minutes after the road traffic had been temporally suspended. The most recent rainfall occurred in the period of 26-27.09.2015, while the last street cleaning took place at night between 30.09 and 1.10.2015.

\subsection{Physical examination of the collected samples}

The dust samples collected from each street were unified and weighed together with the relative humidity and granulometric distribution analysis performed. Determination of the granulometric composition of the dust for the particle size above $0.071 \mathrm{~mm}$ was carried out using the sieving methodology in accordance with the Polish Standard PN-R-04032. The granulometric composition of the dust fraction below $0.071 \mathrm{~mm}$ (the smallest fraction received after sifting on sieves) in the range of $0.00002 \mathrm{~mm}$ to $2 \mathrm{~mm}$ was determined using Mastersizer 2000 (Malvern Instruments) laser diffraction particle size analyser. The wet method was used for the granulometric analysis with propan-2-ol dispersion agent. Analysis was performed for each sample twice, once without ultrasound and once with ultrasound application to assist the agglomerates separation within the analysed dust. 


\subsection{Methodology for estimating re-entrained road dust emission}

Re-entrained particulate matter emissions from the analysed road sections were determined in accordance with the U.S. EPA guidelines [28]. In the first step, the emission factors for resuspended road dust was determined based on the measured value of the road silt load (sL) in $\mathrm{g} \cdot \mathrm{m}^{-2}$ and the average mass of the vehicles on the road in $\mathrm{Mg} \cdot$ vehicles $^{-1}$. The dust emission factor was calculated based on the road type, depending on the average daily traffic expressed in vehicles $\cdot \mathrm{day}^{-1}$. The emission factor unit is $\mathrm{g} \cdot \mathrm{km}^{-1} \cdot$ vehicles $^{-1}$. The average vehicle weight was calculated on the basis of the vehicle structure information derived from periodic measurements of the traffic intensity and vehicle structure carried out for the analysed sections of considered roads. The emission rate was quantified as a function of time, since the traffic intensity is strongly dependent on the time of the day.

According to the methodology applied in the study, three aspects were taken into consideration when estimating the road dust emission rates: traffic intensity in vehicles $\cdot \mathrm{h}^{-1}$ or vehicles·day ${ }^{-1}$, length of the road section in $\mathrm{km}$ and the number of hours in the year during which the atmospheric precipitation intensity reached at least $0.245 \mathrm{~mm} \cdot \mathrm{h}^{-1}$. Only the results of calculations of hourly maximum emission rates in $\mathrm{kg} \cdot \mathrm{h}^{-1}$ were presented in the study.

\subsection{Methodology for estimating the impact of resuspended PM10 on air quality}

The assessment of the influence of the re-entrained road dust PM10 emission on air quality was conducted for one of the roads considered in the study (i.e. Krasinskiego Av.) located within the street canyon. Calculations were carried out using the CALINE4 dispersion model for predicting pollutant concentrations from road transport [30]. Two variants of reentrained dust emissions were adopted. In option 1, the value of resuspended dust emission was determined on the basis of the actual road silt load $\left(\mathrm{sL}\right.$ in $\left.\mathrm{g} \cdot \mathrm{m}^{-2}\right)$, whereas in variant 2 the emission value was estimated based on the reference values specified in the U.S. EPA methodology [28].

\section{Results and discussion}

Performed physical analysis verified low humidity of the collected samples. The moisture content in relation to the dry mass of the samples ranged from 0.256 to $1.693 \%$, with an average value of $0.626 \%$ and a standard deviation of $0.377 \%$. Analysis of the granulometric composition of the samples (Table 1) showed, that the dust deposited on the analysed roads mainly consisted of coarse particles of 75-500 $\mu \mathrm{m}$ and $50-2000 \mu \mathrm{m}$ in diameter. On average, they contribute to 55 and $32 \%$ of the analysed samples mass, respectively. The fraction of fine particles below $75 \mu \mathrm{m}$, that can be lifted by travelling vehicles as a result of turbulences, ranges from 1.73 to $4.10 \%$. The analysis results lead to a conclusion that the largest dissimilarities in the granulometric distributions obtained with and without ultrasound application were observed for the particle size up to $10 \mu \mathrm{m}$. Differences between percentage share of the 0-2.5 $\mu \mathrm{m}$ and the $2.5-10 \mu \mathrm{m}$ particles for both variants are equal to 28.9-54.5 (with ultrasound application) and 43.6-75.6\% (without ultrasound), which indicates that in the extreme cases the effect of ultrasound application increased the share of the $0-2.5 \mu \mathrm{m}$ particles even by $71.1 \%$ and the $2.5-10 \mu \mathrm{m}$ particles by $56.4 \%$. Therefore, the results of the granulometric analysis of the dust determined with the application of ultrasound were used for the emission calculations. 
Table 1. The results of granulometric distribution analysis of the dust collected from the analysed streets performed with and without ultrasound application.

\begin{tabular}{|c|c|c|c|c|c|c|c|}
\hline \multirow[b]{2}{*}{ Street name } & \multirow{2}{*}{$\begin{array}{l}\text { Analysis } \\
\text { with (+) or } \\
\text { without (-) } \\
\text { ultrasound } \\
\text { application }\end{array}$} & \multicolumn{6}{|c|}{ Particle fraction shares [\% w/w] } \\
\hline & & $\begin{array}{c}0-2.5 \\
\mu \mathrm{m}\end{array}$ & $\begin{array}{c}2.5-10 \\
\mu \mathrm{m}\end{array}$ & $\begin{array}{c}10-75 \\
\mu \mathrm{m}\end{array}$ & $\begin{array}{c}75-500 \\
\mu \mathrm{m}\end{array}$ & $\begin{array}{c}500-2000 \\
\mu \mathrm{m}\end{array}$ & $\begin{array}{c}>2000 \\
\mu \mathrm{m}\end{array}$ \\
\hline \multirow{2}{*}{ Lea St. } & - & 0.05 & 0.18 & 3.02 & 68.31 & 26.68 & 1.76 \\
\hline & + & 0.09 & 0.24 & 3.07 & 68.15 & 26.69 & 1.76 \\
\hline \multirow{2}{*}{ Reymonta St. } & - & 0.03 & 0.10 & 1.46 & 52.54 & 39.58 & 6.28 \\
\hline & + & 0.09 & 0.22 & 1.41 & 52.39 & 39.60 & 6.29 \\
\hline \multirow{2}{*}{ Reymonta St.* } & - & 0.04 & 0.12 & 1.57 & 32.72 & 31.97 & 33.58 \\
\hline & + & 0.10 & 0.26 & 1.53 & 32.53 & 31.98 & 33.59 \\
\hline \multirow{2}{*}{$\begin{array}{l}\text { Krasinskiego } \\
\text { Av. }\end{array}$} & - & 0.07 & 0.29 & 2.55 & 66.68 & 29.01 & 1.39 \\
\hline & + & 0.25 & 0.66 & 2.30 & 66.27 & 29.12 & 1.40 \\
\hline \multirow{2}{*}{$\begin{array}{l}\text { Armii } \\
\text { Krajowej St. }\end{array}$} & - & 0.10 & 0.35 & 3.54 & 59.36 & 35.26 & 1.39 \\
\hline & + & 0.18 & 0.50 & 3.43 & 59.21 & 35.28 & 1.39 \\
\hline
\end{tabular}

* sample collected only from the road surface

One of the main objectives of the study was to determine the specific parameter values (silt load $-\mathrm{sL}$ ) for the analysed road sections characterizing the road dust loading of particle size up to $75 \mu \mathrm{m}$. In the Fig. 1 the sL parameter values for the analysed roads are presented, which were determined based on the weight and granulometric distribution of the samples. The values of sL parameter for the considered streets are characterised by large discrepancies, which result from the type of the road, different traffic intensity as well as other factors, i.e. undergoing constructions near the road. The lowest value of the $\mathrm{sL}$ parameter of $0.1 \mathrm{~g} \cdot \mathrm{m}^{-2}$ determined for Reymonta St.* is connected to the fact that the corresponding sample was collected only from the road surface excluding the area at the curb.

Calculated values of the sL parameter for the analysed roads and its reference values derived from the U.S. EPA guidelines [28] were used to estimate both measured and reference values of the PM10 emission rates (Fig. 2). On the basis of the determined emission factors and the actual traffic conditions on roads during peak hours, the actual and reference PM10 emission rates from the considered roads were calculated (Fig. 3).

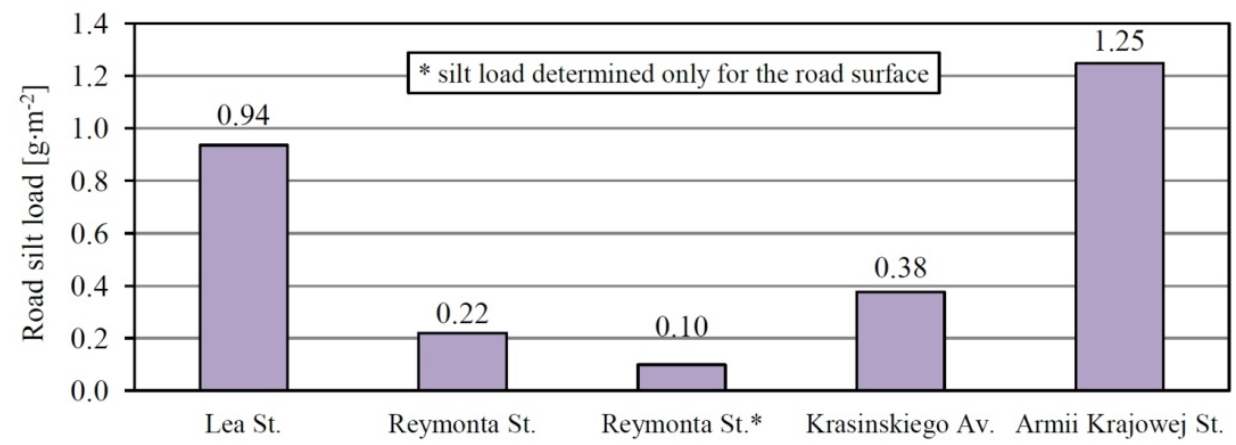

Fig. 1. Actual road silt load (sL) calculated for considered streets (Reymonta St.* - sL calculated based on the dust collected only from the road surface) 


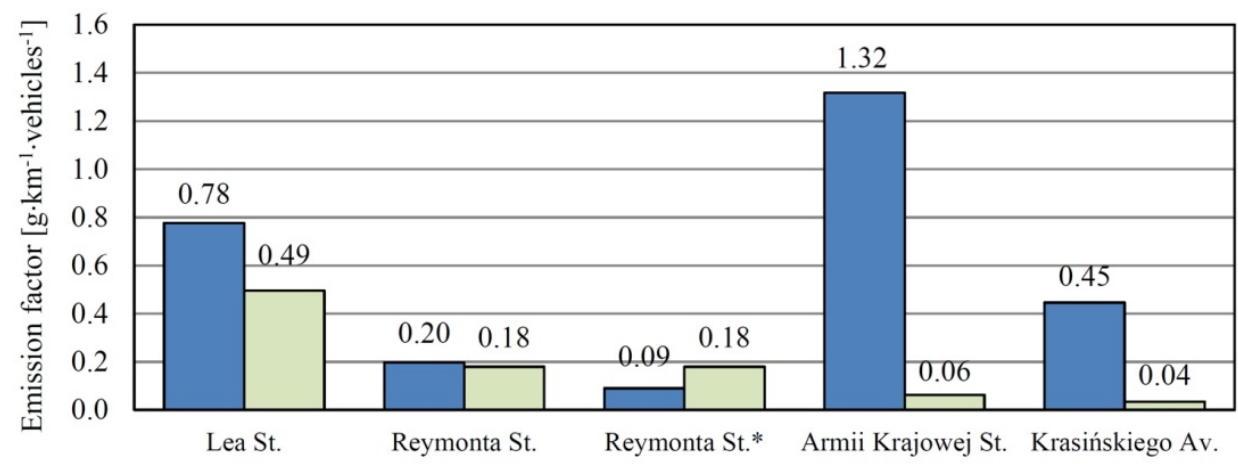

$\square$ Measured values (variant 1) $\quad \square$ Reference values (variant 2)

Fig. 2. Measured and reference values of the PM10 emission factors from the analysed streets (Reymonta St.* - emission factor calculated based on the dust collected only from the road surface)

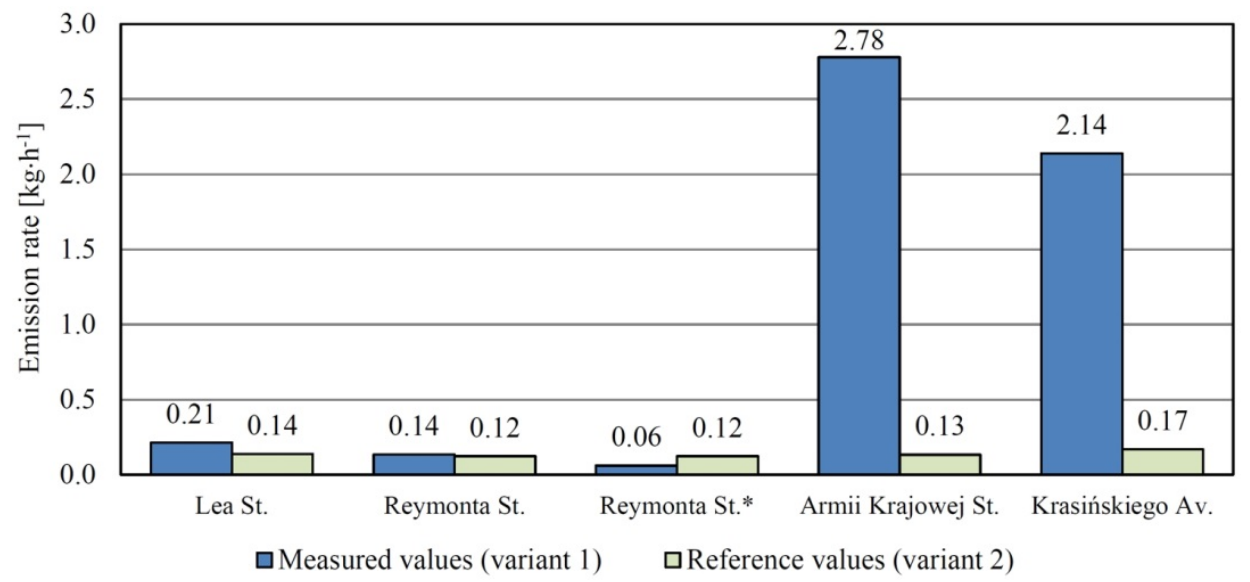

Fig. 3. Comparison of the maximum 1-hour PM10 dust emission rates from the analysed streets based on the measured and reference values of the sL silt load parameter (Reymonta St.* - emission rate calculated based on the dust collected only from the road surface)

Comparative analysis of the actual and reference hourly emission rates showed that in most cases the values of the actual emissions were higher than the reference data. The only exception is the Reymonta St.*, where the actual value of the resuspended PM10 emission was lower than the one obtained from the reference silt load values. The largest discrepancy was found in the case of Armii Krajowej St. where the actual emission is more than 20 times higher than the reference value. Emission rate of this magnitude resulted from additional pollution source on the Armii Krajowej St. in the form of vehicles from the nearby construction site.

Calculated the actual and reference maximum 1-hour PM10 emission values were used to predict the effect of this emission on the modelled PM10 air concentrations across the cross-section in the Krasinskiego street canyon. The concentrations based on actual emission rates are presented in the Fig. 4, while those based on the reference emissions are shown in the Fig. 5. In addition, for both cases the influence of different atmospheric stability conditions on the calculated concentrations was analysed. The presented data were determined for the three Pasquill-Gifford-Turner (PGT) dispersion parameters corresponding to the following atmospheric stability conditions: extremely unstable (PGT $=$ $1)$, neutral $(\mathrm{PGT}=4)$ and extremely stable $(\mathrm{PGT}=7)$. 
The results show that the highest PM10 concentration is concentrated directly above the roadway axes. Moreover, it is proportional to the traffic intensity of the corresponding roadway. On the other hand, within the area of a green belt separating two roadways a drastic decrease in the maximum 1-hour PM10 concentrations is observed. This results from the fact that the modelled wind direction parallel to the road axis is dominant in street canyons. In the adopted calculation scenario, a small deviation from the standard wind direction $\left(\sigma_{\mathrm{WD}}\right)$ of $15^{\circ}$ was applied taking into account that the wind in this area is incapable of large deviations due to the continuous barrier of buildings creating the canyon.

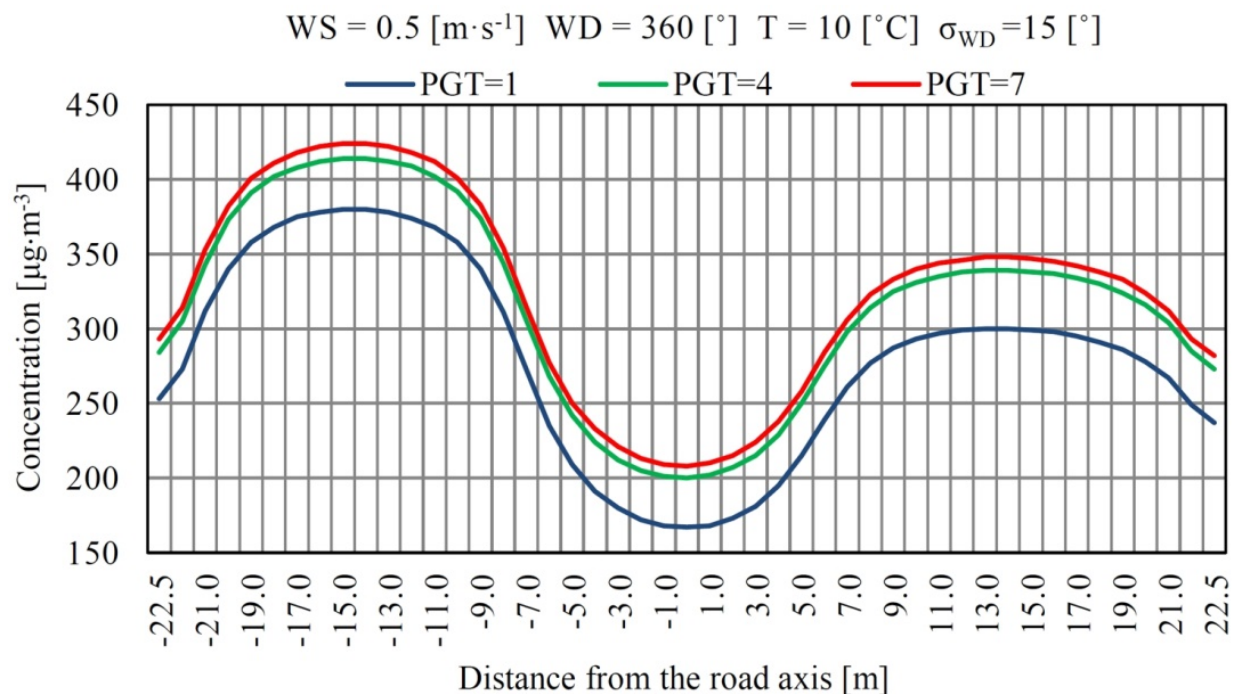

Fig. 4. Distribution of the maximum 1-hour PM10 concentrations in the Krasinskiego street canyon cross-section for different atmospheric stability conditions and the actual emission rates (based on the actual road silt load - sL)

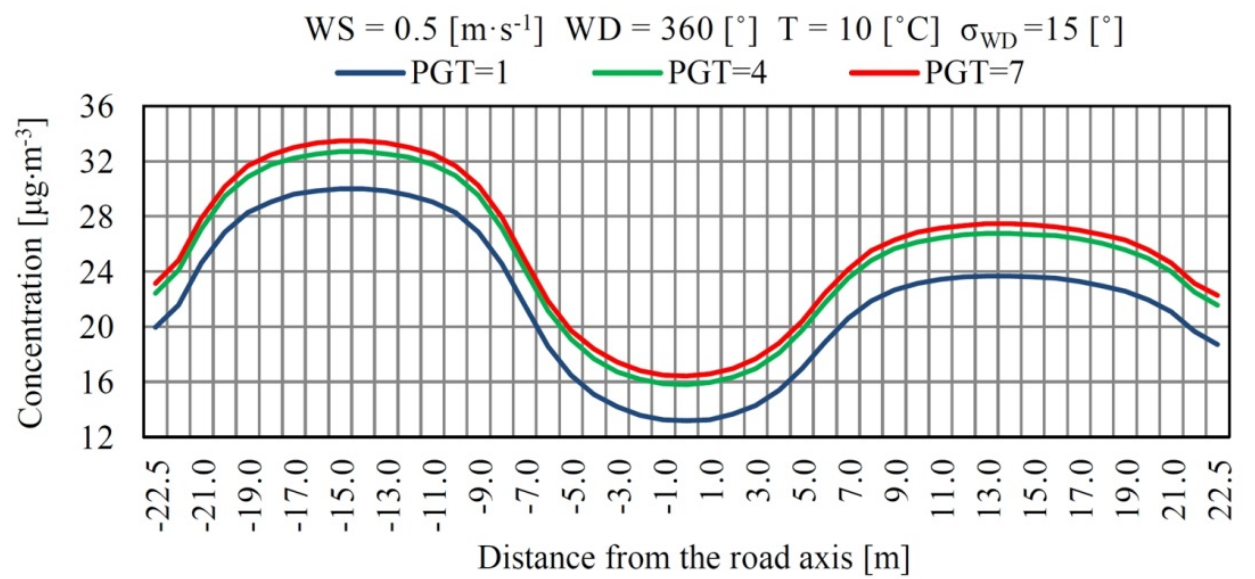

Fig. 5. Distribution of the maximum 1-hour PM10 concentrations in the Krasinskiego street canyon cross-section for different atmospheric stability conditions and the reference emission rates (based on the reference road silt load - sL)

Comparative analysis of the PM10 emission calculation results obtained based on the reference and the actual road silt load showed considerably high discrepancies in the modelled PM10 concentrations. Within the green belt area between the roadways where the 
air quality monitoring station is located, determined PM10 levels for the actual emission rates range from 170 to $210 \mu \mathrm{g} \cdot \mathrm{m}^{-3}$, whereas the concentrations for the reference emission values range from 13 to $17 \mu \mathrm{g} \cdot \mathrm{m}^{-3}$, with the largest values occurring during extremely stable atmospheric conditions. At the roadway axes, the concentrations calculated for both variants are approx. 2 times higher. Comparison of the modelling results and measured PM10 concentrations at the analysed air quality monitoring station during non-heating period indicates that the outcomes based on the road dust emission rate calculations using the reference value of the sL parameter are more reliable. The results of the analysis confirm that the sample collection of the deposited dust for the purpose of assessing the impact of resuspended road dust emissions on the PM10 concentrations in the air should be limited only to the road surface (excluding area at the curb).

Comparison of the modelling results with PM10 air concentrations observed at this location (traffic station) in 2014-2016 during different periods of the year showed that the road dust re-entrainment processes from the Krasinskiego Av. surface in the summer can be responsible for $40-50 \%$, while in the winter even up to $25 \%$ of the total PM10 concentrations in the air. Moreover, the outcomes pointed to a significant influence of wind speed on the PM10 concentrations in street canyons. Maximum 1-hour concentrations at wind speed from 0.5 to $5.0 \mathrm{~m} \cdot \mathrm{s}^{-1}$ range from 31 to $3 \mu \mathrm{g} \cdot \mathrm{m}^{-3}$, but only a slight increase in wind speed, e.g. from 0.5 to $1.0 \mathrm{~m} \cdot \mathrm{s}^{-1}$ leads to decrease in maximum 1-hour PM10 concentrations in the air by up to $60 \%$. This tendency is observed as well at urban background stations located in Krakow [31,32].

\section{Conclusions}

Conducted research proved that dust particles resuspended from roads may constitute an important share in the total PM10 air concentrations in the vicinity of transport routes, especially in urban areas that are insufficiently ventilated (e.g. inside street canyons). These observations are consistent with findings in the study discussing the same considered street canyon in 2012 [33]. In addition, they pointed to the possible major impact of the fine dust emitted from the road surface in the Krasinskiego Av. in Krakow on the observed PM10 concentrations in the air.

Conclusions formulated in the study allowed to verify the applicability of the sL parameter reference value presented in the U.S. EPA guidelines [28] for considered road types in Krakow. Positive verification of the PM10 emissions from roads based on the assumed sL values confirmed that the appropriate practice of dust sample collection for the purpose of evaluating the impact of this emission on air quality is to exclude areas near the curb and focus on the road surface alone. Nonetheless, the PM10 emissions calculated on the basis of the dust material collected from both the road surface and the area at the curb accurately represent the situation corresponding to the high PM10 concentrations (peaks) observed periodically at the traffic air quality monitoring stations resulting from the mechanical street cleaning events. However, this statement requires further experimental research and analysis on such episodes.

Reduction of the re-entrained road dust emissions is therefore an important challenge facing municipalities. Decrease in the amount of particles deposited on the roads can be attained, for example, as a result of intense atmospheric precipitation, but the preventive measures undertaken by urban services responsible for maintaining the cleanliness of the streets are crucial. As denoted in the work [25], these actions should involve regular dusting and cleaning of the streets, pavements and curbs, as well as the introduction of legal regulations and control measures to prevent further street pollution caused by vehicles leaving unpaved roads, construction sites or transporting uncovered dusty/powdery cargoes. 
The paper has been prepared within the scope of the AGH UST statutory research no. 11.11.150.008. The authors would like to thank the authorities and municipal services of the city of Krakow for their assistance in carrying out the research.

\section{References}

1. I. Düring, A. Lohmeyer, L. Zippack, Auswertung der Messungen des BLUES während der Abspülmassnahme im Bereich der Messstation Neuenlander Straße in Bremen (2005)

2. W. Bächlin, I. Düring, A. Lohmeyer, L. Zippack, Auswertung der Messungen des BLUME während der Abspülmaßnahme am Abschnitt Frankfurter Allee 86 (2004)

3. I. Düring, T. Hoffmann, A. Lohmeyer, E. Nitzsche, Auswertung der Messungen des Blume während der Verbesserten Strassenreinigung am Abschnitt Frankfurter Allee 86 (2007)

4. G. Omstedt, B. Bringfelt, C. Johansson, Atmos. Environ. 39, 6088 (2005)

5. C.-H. Chang, R.N. Meroney, J. Wind Eng. Ind. Aerodyn. 91, 1141 (2003)

6. N. Bukowiecki, P. Lienemann, M Hill, M. Furger, A. Richard, F. Amato, A.S.H. Prévôt, U. Baltensperger, B. Buchmann, R. Gehrig, Atmos. Environ. 44, 2330 (2010)

7. F. Amato, S. Nava, F. Lucarelli, X. Querol, A. Alastuey, J.M. Baldasano, M. Pandolfi, Sci. Total. Environ. 408, 4309 (2010)

8. F. Carraz, K.G. Taylor, S. Stainsby, D. Robertson, North West Geography 6, 1 (2006)

9. P. Pant, R.M. Harrison, Atmos. Environ. 77, 78 (2013)

10. M. Marjamäki, J. Keskinen, Particulates, Characterisation of Exhaust Particulate Emissions from Road Vehicles, Deliverable 2, Vehicle exhaust particulates characterisation, properties, instrumentation and sampling requirements (EC, DG TrEn, 2001)

11. F. Amato, X. Querol, C. Johansson, C. Nagl, A. Alastuey, Sci. Total. Environ. 408, 3070 (2010)

12. M. Abu-Allaban, J.A. Gillies, A.W. Gertler, R. Clayton, D. Proffitt, Atmos. Environ. 37, 5283 (2003)

13. A. Thorpe, R.M. Harrison, Sci. Total. Environ. 400, 270 (2008)

14. F. Amato, O. Favez, M. Pandolfi, A. Alastuey, X. Querol, S. Moukhtar, B. Bruge, S. Verlhac, J.A.G. Orza, N. Bonnaire and others, Atmos. Environ. 129, 114 (2016)

15. F. Amato, A. Karanasiou, P. Cordoba, A. Alastuey, T. Moreno, F. Lucarelli, S. Nava, G. Calzolai, X. Querol, Environ. Sci. Technol. 48, 8069 (2014)

16. F. Amato, A. Karanasiou, T. Moreno, A. Alastuey, J.A.G. Orza, J. Lumbreras, R. Borge, E. Boldo, C. Linares, X. Querol, Atmos. Environ. 61, 580-587 (2012)

17. F. Amato, M. Pandolfi, T. Moreno, M. Furger, J. Pey, A. Alastuey, N. Bukowiecki, A.S.H. Prevot, U. Baltensperger, X. Querol, Atmos. Environ. 45, 6777 (2011)

18. M. Crippa, P.F. DeCarlo, J.G. Slowik, C. Mohr, M.F. Heringa, R. Chirico, L. Poulain, F. Freutel, J. Sciare, J. Cozic and others, Atmos. Chem. Phys. 13, 961 (2013)

19. O. Favez, H. Cachier, J. Sciare, Y. Le Moullec, Atmos. Environ. 41,7969 (2007)

20. F. Shou-bin, T. Gang, L. Gang, H. Yu-hu, Q. Jian-ping, C. Shui-yuan, Atmos. Environ. 43, 6003 (2009)

21. J. Chow, J. Watson, D. Lowenthal, C. Frazier, B. Hinsvark, L. Pritchett, Wintertime PM10 and PM2.5 chemical compositions and source contributions in Tucson, Arizona, 
In: J. Chow, D. Ono (eds.), Transactions, PM10 Standards and Nontraditional Particulate Controls (Air Waste Management Assoc., Pittsburgh, Pennsylvania, 1992)

22. M. Rexeis, S. Hausberger, Atmos. Environ. 43, 4689 (2009)

23. R. Pitt, R. Bannerman, R. Sutherland, The Role of Street Cleaning in Stormwater Management (Water World and Environmental Resources Congress, American Society of Civil Engineers, Salt Lake City, 2004)

24. G. Ionescu, T. Apostol, E.C. Rada, M. Ragazzi, V. Torretta, U.P.B. Sci. Bull., Series D 75, 2, 175 (2013)

25. B. Benito-López, M.R. Moreno-Enguix, J. Solana-Ibañez, Waste Manage. 31, 1099 (2011)

26. X. Querol X, A. Alastuey, T. Moreno, M.M. Viana, S. Castillo, J. Pey, S. Rodríguez, B. Artiñano, P. Salvador, M. Sánchez and others, Atmos. Environ. 42, 3964-3979 (2008)

27. M. Rzeszutek, A. Szulecka, Ekonomika Transportu i Logistyka, 59, 339 (2016)

28. U.S. EPA, AP 42 Fifth Edition, I, 13, Miscellaneous Sources, 13.2.1 Paved Roads (2011)

29. U.S. EPA, AP 42 App. C1, Procedures For Sampling Surface/Bulk Dust Loading (1993)

30. P.E. Benson, CALINE4 - a dispersion model for predicting air pollutant concentrations near roadways (California Department of Transportation, Sacramento, Report No. FHWA/CATL-84/15, 1989)

31. R. Oleniacz, M. Bogacki, M. Rzeszutek, A. Kot, Meteorological factors affecting air quality in Krakow, In: J. Konieczyński (ed.), Ochrona powietrza w teorii i praktyce, Tom 2 (IPIŚ PAN, Zabrze, 2014)

32. R. Oleniacz, M. Bogacki, A. Szulecka, M. Rzeszutek, M. Mazur, JCEEA, 33, 315 (2016)

33. M. Bogacki, M. Rzeszutek, K. Heba, JCEEA, 33, 63 (2016) 